\title{
Structural Metamorphosis of the Fe(III) Gallate - a Historical Iron Gall Ink
}

Peter Y. Zavalij, Lauren M. Stevens, Aldo Poncel, Sarah K. Gibbons, Karen J. Gaskell, Lynn B. Brostoff ${ }^{2}$, Bryan W. Eichhorn

Department of Chemistry and Biochemistry, University of Maryland, College Park, MD, USA; ${ }^{1}$ Department of Materials Science and Engineering, University of Maryland, College Park, MD, USA; ${ }^{2}$ Preservation Research and Testing Division, Library of Congress, Washington, DC, USA.

Until the last century iron gall ink (IGI) was by far the most common ink used to pen many of the most important documents and drawings in human history. Despite such historical importance, there was little known about the composition, chemical properties and structure of iron-gallate complex $\mathrm{Fe}\left(\mathrm{C}_{7} \mathrm{H}_{3}+\mathrm{O}_{5}\right) \cdot \mathrm{nH}_{2} \mathrm{O}$ - the main pigment of IGI. The main obstacle in finding the crystal structure was the amorphous nature of IGI. However iron gallate can be also prepared in crystalline form which then transforms to amorphous. We present here five crystalline polymorph modifications of IGI, all but one of which are newly discovered structures, and discuss their composition and structural transformation from one to another and to amorphous state. Interestingly, all IGI structures maintain the same chemical connectivity of 3D octahedral Fe(III) gallate metal-organic framework despite different Fe oxidation state, water content, lattice dimensions and sometimes symmetry. They all can be viewed as different stages of the crystalline to amorphous transition. 